helped to adjudicate question categories, write the paper and helped with study oversight. Jay Monnahan helped to collect the data. Bobby Peters, Charles Jennissen and Dean Anderson helped to categorise the questions.

\section{REFERENCES}

1 Graber MA, Randles BD, Ely JW, et al. Answering clinical questions in the emergency department. Am J Emerg Med (in press).
2 Ely JW, Osheroff JA, Gorman PN, et al. A taxonomy of generic clinical questions: classification study. BMJ 2000;321:429-32.

3 Reichert S, Simon T, Halm EA. Physicians' attitudes about prescribing and knowledge of the costs of common medications. Arch Intern Med 2000;160:2799-803.

4 Glickman L, Bruce EA, Caro FG, et al. Physicians' knowledge of drug costs for the elderly. J Am Geriatr Soc 1994;42:992-6.

5 Shrank WH, Asch SM, Joseph GJ, et al. Physicians' perceived knowledge of and responsibility for managing patients' out-of-pocket costs for prescription drugs. Ann Pharmacother 2006;40:1534-40.

\title{
IMAGES IN EMERGENCY MEDICINE
}

\section{Ring enhancing lesion on CT scan: metastases or a brain abscess?}

\section{Anil K Agarwal, Ranjna Garg, Mary Simon}

A 28-year-old man presented to eye casualty with left orbital headache. The physical examination was normal but fundoscopy showed left sided papilloedema. There were no features indicative of infection/sepsis, and no history of primary malignancy. Blood results were not suggestive of infective pathology. Computed tomographic (CT) brain scan showed multiple ring enhancing lesions, suggestive of multiple cerebral metastases and/or brain abscess (figs 1 and 2). Brain biopsy on immunohistochemistry staining using MelanA and HMB45 showed melanin pigment within disorderly arranged cells, confirming the diagnosis of malignant melanoma (fig 3).
Malignant melanoma was diagnosed when our patient presented with cerebral metastases. In $70-80 \%$ cases of melanoma recurrence, metastases are seen in the brain. Cerebral metastases in melanoma have prognostic value. ${ }^{1}$ The central nervous system is a common site for metastases from many malignancies including melanoma. Multiple ring enhancing lesions are suggestive of metastases or abscess. Brain biopsy is usually not necessary in all cases as diagnosis of cerebral metastases is usually apparent from the history. Ring enhancing lesions should be differentiated by appropriate investigation.

Emerg Med J 2007;24:706.

doi: 10.1136/emj.2006.041913

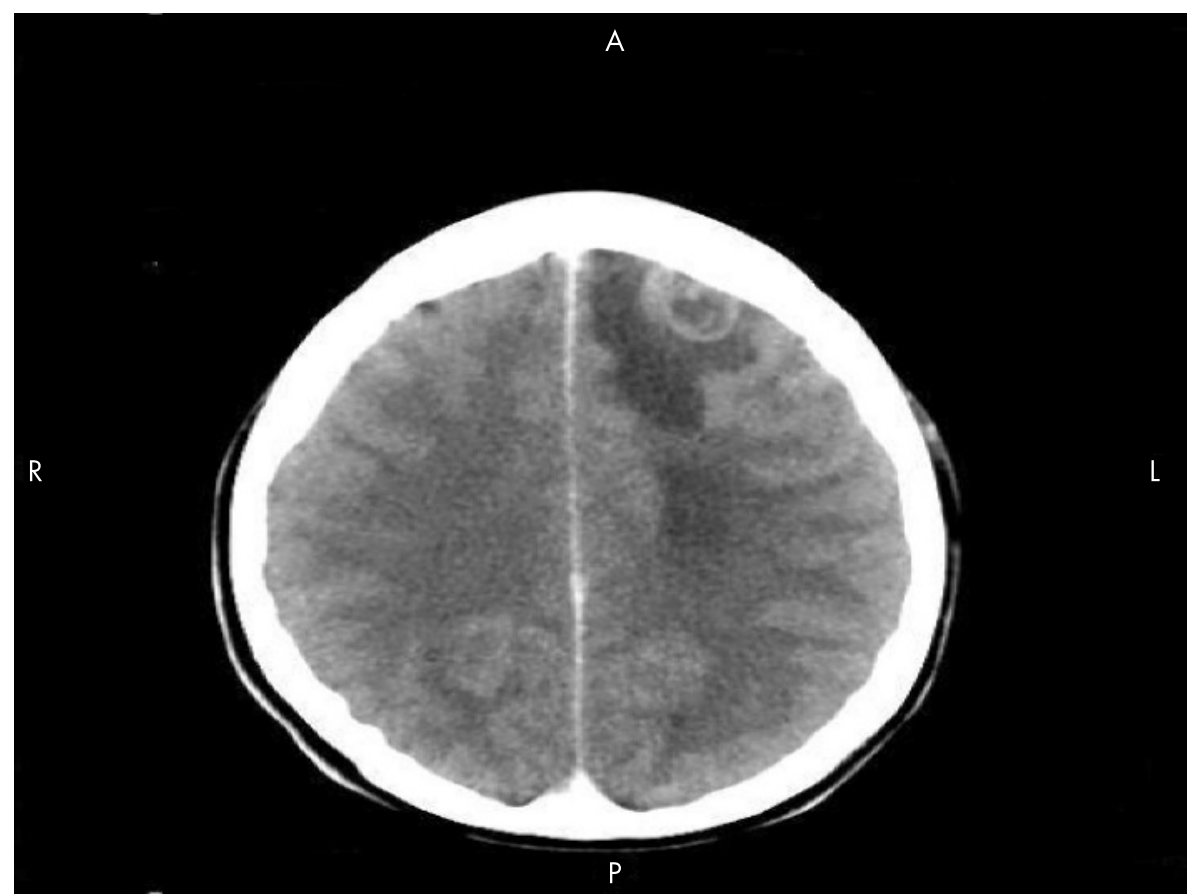

Figure 1 CT scan brain showing ring enhancing lesions.

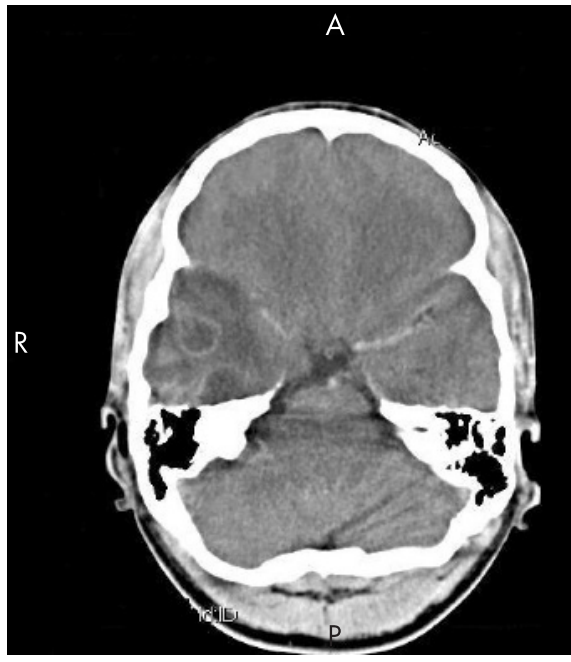

Figure 2 CT scan brain showing ring enhancing lesions.

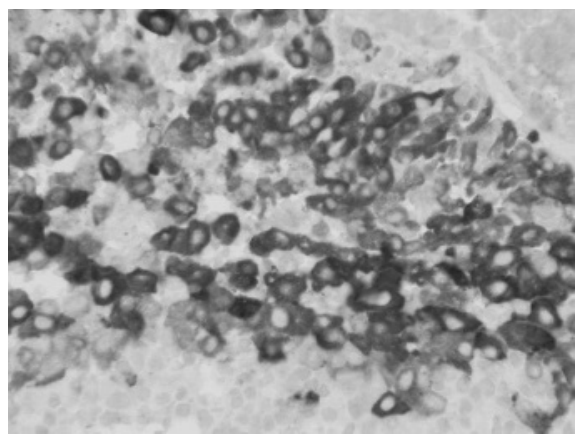

Figure 3 Melanin pigment in metastatic malignant melanoma on immunohistochemistry using Melan A staining.

\section{Authors' affiliations}

A K Agarwal, R Garg, M Simon, City Hospital, Birmingham, UK

Correspondence to: Dr Anil Kumar Agarwal, City Hospital, Birmingham, UK; anilbaliuk@yahoo. co.uk

Accepted 6 September 2006

Competing interests: None.

\section{REFERENCE}

1 Balch CM, Soong SJ, Murad TM, et al. A multifactorial analysis of melanoma. IV. Prognostic factors in 200 melanoma patients with distant metastases (stage III). J Clin Oncol 1983;1:126-34 